\title{
The Study on the Important Role of Foreign Language Economy for the Development of Shaanxi Foreign Tourism Industry
}

\author{
Li Xiaoni \\ International education college, Xi'an Peihua University, Chang'an campus, Chang'an district, Xi'an, \\ China
}

Keywords: Foreign language economy; foreign travel

\begin{abstract}
Foreign tourism is a leading industry in the development of tourist industry. Foreign language economy is an important part of foreign tourism. Shaanxi has the rich tourism resources, and the tourism cooperation between Shaanxi and other countries is highly correlated, and there are a lot of cooperation and consensus, strong folk impetus, and great potential and space for development. But the vulnerable openness affects the effective cooperation between Shaanxi and other countries. Therefore, with the help of economic influence on improving openness and promote the development of Shaanxi foreign-related tourism. So, Building Shaanxi as the golden section is the top priority nowadays.
\end{abstract}

\section{Introduction}

The promotion of global economic integration brings country economies into the world, and the development of Shaanxi economy also needs shift to export-oriented economy. Shaanxi economy development needs to build the open economy system, explore the historical and cultural resources, foster Shaanxi style, with Chinese characteristics, time characteristics and the influence of culture brand, and promote cultural soft power, promote economic development in Shaanxi economic zone and culture prosperity. In order to build an open economy system and cultivate a cultural brand with international influence, foreign language has become a basic requirement. Without foreign language, all foreign-related economic activities will not speak of.

\section{The concept of foreign language economy}

Linguistic economics points out that language ability is a kind of human capital, which has the characteristics of linguistic economics, Zhang Defu (2005) put forward that the linguistic economics based on the situation of our country, and pointed out that foreign language based on economy is a unique economic phenomenon in the process of global economic integration(2).Culture has the characteristics of nationality and diversity, and it makes foreign language as the hardware aid of foreign tourism tools and economic exchanges, and it is also one of the key elements to carry out foreign economic in the background of economic globalization in our country, and it occupies an important position in the foreign-related tourism and economic activities. Foreign language economy runs through in all external economic activities. It is not only a necessary medium for regional economic development and personal development, but also brings great economic benefits for local development. Foreign language economy not only can be a tool acquiring knowledge and skills, but also be applied in society and economic life, and bring economic benefits to both countries and individuals. Foreign language economy can promote globalization of a country and promote science communication and technology update in the knowledge economic area. It also can promote the transformation of science and technology into productivity, and create certain economic benefits and international competitiveness, also can promote the development of regional economy.

Foreign language economy has the following characteristics: 1. It is the carrier of foreign languages other than the native language and bases on the background of global economic integration.2. The investment and consumption of foreign language education lead to prosperous language economic activities, and promote various economic and cultural activities which related to 
language, and promote the prosperity of language and cultural markets.3. As the economic capital, foreign language economy has its own value in use and benefit, which determines China's quality and speed of integration into the global and regional economic system.4. Foreign language economy is an important part of the foreign economy, which is the necessary condition and guarantee for promoting the effective operation of Shaanxi foreign-related tourism.

\section{Analysis on the feasibility of developing foreign tourism in Shaanxi}

\subsection{Shaanxi Xi'an is the starting point and core area of the Silk Road economic belt.}

$\mathrm{Xi}$ 'an, as the capital city of Shaanxi province, is the starting point and core area of the Silk Road economic belt, and is also the permanent site of Eurasian economic BBS. Xi'an has advantageous and geographical location, and long standing history culture. With enormous science, educational and tourism resources, Xi'an is completely feasible to conduct foreign-related tourism. As the regional cooperation has become the mainstream way of national cooperation, tourism has become an important part of national output and pillar industry in Shaanxi province. Foreign tourism have furthered the rising trend proportion of GDP in Shaanxi area year by year. In 2016, the growth of inbound tourism in Shaanxi province has shifted from steady growth to accelerated development. The number of tourists and the figure international tourism revenue increased by more than $15 \%$, which exceed the national average of 11.61 and 11.31 percentage respectively. In 2016, Shaanxi province received 228.52 million foreigners, with year-on-year growth of $17.7 \%$, accounting for $67.57 \%$ of the inbound tourists. Foreign people market remains the main body of the inbound tourism. The total number of tourists from Korea, including South Korea, the United States and the UK reached 8.977 million, accounting for 39.28 percent of the total number of foreigners, which make it the main force in the foreign market. (Data source: Shaanxi tourism bureau, 2016 statistics bulletin of tourism economic development of Shaanxi province.

\subsection{Shaanxi is the major tourism province in China's western region}

Shaanxi is major tourism province in China's western region and has very rich tourism resources. It has more advanced tourist attractions, especially its history of more than 3100 years in urban construction and colorful cultural heritage, which make Shaanxi one of the best places and attracts overseas tourists come to China. After more than 20 years development, Shaanxi province has a certain scale of tourism. Shaanxi province, Xi'an as the ancient capital of 13 dynasties is also one region that started the tourism industry earlier in the world. Xi'an is the bridgehead of tourism and the leader of international tourism industry in Shaanxi, and which occupies an important position in the cultural tourism of China's Silk Road.

\subsection{Shaanxi Xi'an has the perfect developed land and resources}

Shaanxi Xi'an has perfect developed land and air transportation network, and also has rich science and education resources. The comprehensive soft power of Shaanxi is the 8th in China. It is one of the five largest education bases in China, and the number of universities is third in the whole country. Most universities have foreign language majors, and foreign language training institutions are numerous in Shaanxi province. Nowadays, Shaanxi Xian is speeding up the pace of construction of international metropolis. These advantages are the opportunities to build the Silk Road economic belt with the help of foreign language economy. Shaanxi province should give play to growth effect and accelerate the process of world economy. In order to promote cross-regional cooperation of Shaanxi foreign tourism we should provide a feasible and necessary condition. 


\section{The role of foreign language economy in the development for foreign tourism industry in Shaanxi}

\subsection{Foreign tourism resources are an important industry for economic development in Shaanxi}

Driven by foreign language economy, Shaanxi has become an important area of China's tourism industry. Tourism has become the largest stable export industry and sunrise industry because of its wide coverage, earning foreign exchange quickly and the highest openness. Foreign language economy is main supporting tool and platform that Shaanxi tourism advertisement must rely on. Foreign language economy can carry out foreign tourism integration into the world tourism industry and is the main way to deal with foreign tourist events and achieve economic goals. It is also an important part of tourism economy where people who engaged in foreign-related tourism can obtain economic benefits directly, and with the help of the foreign language communication platform can get economic benefits indirectly. Foreign language economy is the fundamental factor that Shaanxi province build international tourism brand by virtue of the Silk Road economic belt. It is also the key point to construct international tourism city and integrate into international pattern of regional tourism cooperation initiatively and innovatively, and meanwhile promote the development of barrier-free tourism.

\subsection{Through foreign tourism platform to cultivate foreign language talents}

Cultivating foreign language talents is related to the internationalization degree and influence of Shaanxi tourism industry. It is an important part of the strategy of talents developing in Shaanxi province. There are five targets of oral English and translation ability, interpersonal communication and coordination ability, independent analysis, problem solving ability, cross-cultural communication ability. Market needs international talents to replace the traditional foreign language tool-styled person. Here, the internationalization talents refer to the people who are familiar with national and cultural tourism laws and regulation, familiar with the national tourism market development dynamic, and have international tourism professional skills, know international travel agencies and international hotel, familiar with management knowledge of higher foreign-related tourism. More important they are professional foreign language applied talents. International foreign language professionals can promote development of Shaanxi international travel and cooperation effectively. They can create new growth point for Shaanxi international travel service and change the short board of internationalization development, and also promote Shaanxi foreign tourism market as an omni-directional, multilevel and wide-range pattern(3). At the same time, it is necessary to train foreign language tourism professionals regularly in our province, and focus on increasing the quality of tourism service consciousness, standard consciousness and brand consciousness. At last, we should advocate wisdom tourism and improve the efficiency of Shaanxi foreign-related tourism economy.

\subsection{Tourism industry is important pillar industry for Shaanxi economic growth}

With the help of foreign language economy, hotels, catering industry and tourist agencies in Shaanxi are encouraged to be integrated and cooperated with countries of Silk Road. In particular, the relevant travel agencies in Xi'an can jointly design and develop tourism lines with the help of the government, and jointly build tourism products brand to promote related tourism industry. Relying on positive guidance of foreign language economy and development of information technology and science, Shaanxi province will promote industrialization of tourism culture. Along with the promotion of foreign language economy, the tourism industry will become an important pillar industry for Shaanxi economic growth.

\section{Acknowledgements}

This paper is the research results of school-class project 2017 in Xi'an Peihua University, The 
strategy for the development of foreign tourism industry driving by foreign language economy in xi 'an” with the project number of PHKT17051.

\section{References}

[1] Ren Rong. The Design Principle of English Trademark Words in terms of Economic Value of Language [J]. Foreign Language Teaching, 2002 (5).

[2] Zhang Defu. The Influence of Foreign Language Economy on China's Economic Development. [J].Business research, 2005(24).

[3] Yang Guanghu. Xi 'an: starting as the engine of silk road, building an international tourism city, China travel news, January 9, 2015, edition 009. 